\title{
Pretracheal Lymph Node
}

National Cancer Institute

\section{Source}

National Cancer Institute. Pretracheal Lymph Node. NCI Thesaurus. Code C147455.

A lymph node located anterior to the trachea, between the isthmus of the thyroid gland and the innominate vein. 